\title{
Humoral Response in SARS-CoV-2 Convalescent Compared to Vaccinated Kidney Transplant Patients
}

\author{
Judith Schimpf ${ }^{1}$, Hannelore Sprenger-Mähr ${ }^{1}$, Tamara Davidovic ${ }^{1}$, Karl Lhotta ${ }^{1,2}$ and \\ Emanuel Zitt ${ }^{1,2,3 *}$ \\ ${ }^{1}$ Department of Internal Medicine 3 (Nephrology and Dialysis), Feldkirch Academic Teaching Hospital, Feldkirch, Austria, \\ ${ }^{2}$ Vorarlberg Institute for Vascular Investigation and Treatment NIVIT), Feldkirch, Austria, ${ }^{3}$ Agency for Preventive and Social \\ Medicine (aks), Bregenz, Austria
}

Keywords: SARS-CoV-2, kidney transplantation, vaccination, humoral response, SARS-CoV-2 spike protein

Dear Editors,

Solid organ transplant patients are at high risk for severe or fatal COVID-19 (1), even after two vaccinations (2). Recent studies show, that after a double vaccination course, the antibody response rate is as low as $48 \%$ (3). However, to our knowledge there is no data on differences in the natural or vaccineinduced SARS-CoV-2 humoral immunity evaluated in one and the same cohort of kidney transplant recipients (KTR). Here, we are reporting on and comparing the humoral response in 164 KTR (mean age 59.1 years (range 21-85 years), 61.6\% male). The group included 142 patients who were vaccinated twice (72\% Moderna mRNA-1273 vaccine; 27\% Pfizer/BioNTech mRNA-BNT162b2 SARS-CoV-2 vaccine, $1 \%$ Oxford-AstraZeneca ChAdOx1-COVID-19 vaccine) and 22 patients after symptomatic and PCRconfirmed Covid-19. We assessed the humoral response on average (25th percentile, 75th percentile) 50 days $(33.8,62.0)$ after the second vaccine dose or 90 days $(39.8,143.0)$ after infection by quantifying anti-SARS-CoV-2 spike IgG antibodies. Most patients were treated with tacrolimus (74\%), mycophenolic acid $(71 \%)$ and prednisolone (57\%). Eight percent were treated with belatacept. Convalescent KTR were significantly younger $(p=0.009)$, had lower eGFR $(p=0.021)$ and were more often treated with prednisolone $(p=0.042)$ as shown in Table 1. Seroconversion was defined as an anti-SARS-CoV-2 IgG antibody concentration above the respective cut-off value according to the manufacturer of the assay. Details about the assays in use and their cut-off values are given in the Supplementary Material.

The seroconversion rate in convalescent patients was 90.9 and $48.6 \%$ in vaccinated patients $(p<$ $0.001)$. In the patients treated with belatacept, only one out of $12(8.3 \%)$ vaccinated individuals had a seroconversion, whereas both naturally infected patients showed a response. In a multivariable logistic regression analysis infection compared to vaccination [odds ratio (OR) 18.98; 95\% CI: 3.41, 105.58 ] and transplantation vintage (OR 1.01; 95\% CI: 1.01, 1.02) were associated with a significantly higher likelihood of seroconversion. On the other hand, older age (OR 0.95; 95\% CI: $0.93,0.99$ ) and belatacept treatment (OR 0.13; 95\% CI: $0.02,0.68$ ) significantly decreased the likelihood of seroconversion. All model coefficients and odds can be found in the Supplementary Table S1.

Like our results in convalescent KTR, Magicova et al. recently found a preserved humoral response after SARS-CoV-2 infection comparable to immunocompetent persons in a large Czech cohort of 1,037 kidney transplant recipients with a seroprevalence of $6.8 \%$ during the second infection wave in fall 2020 (4). In line with our findings, recent data in dialysis patients also show a superior humoral immune response in convalescent compared to vaccinated patients (5). Natural infection seems to be a stronger and quantitatively higher antigenic challenge than vaccination. In contrast to intramuscular vaccination, natural infection stimulates the resident immune system of mucous membranes, especially designed to 
TABLE 1 | Characteristics of convalescent and vaccinated kidney transplant patients with and without seroconversion.

\begin{tabular}{|c|c|c|c|c|c|c|c|c|}
\hline & \multirow[t]{2}{*}{ Total $(n=164)$} & \multicolumn{3}{|c|}{ Infection $(n=22)$} & \multicolumn{3}{|c|}{ Vaccination $(n=142)$} & $p-$ \\
\hline & & $\begin{array}{l}\text { Seroconversion } \\
\quad(n=20)\end{array}$ & No seroconversion $(n=2)$ & Total $(n=22)$ & $\begin{array}{l}\text { Seroconversion } \\
\quad(n=69)\end{array}$ & $\begin{array}{c}\text { No } \\
\text { seroconversion } \\
(n=73)\end{array}$ & Total $(n=142)$ & \\
\hline Age (years), mean (SD) & $59.1(13.9)$ & $51.7(15.6)$ & $55.0(1.4)$ & $52.0(14.9)$ & $59.0(51.5,65.0)$ & $62.2(13.4)$ & $60.2(13.4)$ & 0.009 \\
\hline Gender (male), $n$ (\%) & $101(61.6 \%)$ & $14(70 \%)$ & $2(100 \%)$ & $16(72.7 \%)$ & $44(63.8 \%)$ & $41(56.2 \%)$ & 85 (59.9\%) & 0.347 \\
\hline $\begin{array}{l}\text { eGFR }\left(\mathrm{ml} / \mathrm{min} / 1.73 \mathrm{~m}^{2}\right) \text {, } \\
\text { mean (SD) }\end{array}$ & $52.8(17.6)$ & $45.0(14.8)$ & 42.5 (patient 1:49.0; patient 2: 36.0) & $44.7(14.2)$ & $55.2(16.8)$ & $53.0(18.8)$ & $54.0(17.8)$ & 0.021 \\
\hline $\begin{array}{l}\text { Transplantation vintage } \\
\text { (months), median (25th } \\
\text { percentile, } 75 \text { th percentile) }\end{array}$ & $104.5(50.3,174.5)$ & $87.5(34.0,151.5)$ & 207.0 (patient 1: 41.0; patient 2: 373.0) & $87.5(38.0,161.3)$ & $147.0(93.5,223.0)$ & $70.0(37.5,120.5)$ & $108.5(53.0,175.5)$ & 0.361 \\
\hline $\begin{array}{l}\text { Time between antigenic } \\
\text { contact (infection or } \\
\text { vaccination) and antibody } \\
\text { assessment (days), median } \\
\text { (25th percentile, } 75 \text { th } \\
\text { percentile) }\end{array}$ & & $88.0(37.3,118.3)$ & 252.5 (patient 1: 230.0, patient 2: 275.0) & $90.0(39.8,143.0)$ & $51.0(34.5,64.0)$ & $43.0(31.5,60.0)$ & $50(33.8,62.0)$ & 0.001 \\
\hline \multicolumn{9}{|l|}{ Immunosuppression, $n$ (\%) } \\
\hline Prednisolone & 94 (57.3\%) & 15 (75\%) & $2(100 \%)$ & $17(77.3 \%)$ & $30(43.5 \%)$ & $47(64.4 \%)$ & 77 (54.2\%) & 0.042 \\
\hline Tacrolimus & $121(73.8 \%)$ & $17(85 \%)$ & $1(50 \%)$ & $18(81.8 \%)$ & $48(69.6 \%)$ & 55 (75.3\%) & $103(72.5)$ & \\
\hline Mycophenolic acid & $116(70.7 \%)$ & 15 (75\%) & $0(0 \%)$ & $15(68.2 \%)$ & $38(55.1 \%)$ & $63(86.3 \%)$ & $101(71.1 \%)$ & \\
\hline Everolimus & $1(0.6 \%)$ & $0(0 \%)$ & $0(0 \%)$ & 0 & $1(1.4 \%)$ & $0(0 \%)$ & $1(0.7 \%)$ & \\
\hline Sirolimus & $5(3 \%)$ & $0(0 \%)$ & $1(50 \%)$ & $1(4.5 \%)$ & $3(4.3 \%)$ & $1(1.4 \%)$ & $4(2.8 \%)$ & \\
\hline Belatacept & $14(8.5 \%)$ & $2(10 \%)$ & $0(0 \%)$ & $2(9.1 \%)$ & $1(1.4 \%)$ & $11(15.1 \%)$ & $12(8.5 \%)$ & \\
\hline Cyclosporin A & $23(14.0 \%)$ & $2(10 \%)$ & $0(0 \%)$ & $2(9.1 \%)$ & $16(23.2 \%)$ & 5 (6.8\%) & 21 (14.8\%) & \\
\hline Azathioprine & $16(9.8 \%)$ & $2(10 \%)$ & $1(50 \%)$ & $3(13.6 \%)$ & $11(15.9 \%)$ & $2(2.7 \%)$ & $13(9.2 \%)$ & \\
\hline
\end{tabular}

${ }^{a} \mathrm{p}$-value for group comparison infection versus vaccination. 
fight respiratory viral diseases. These considerations and first experience showing a $49-70 \%$ humoral response rate after a third vaccine dose in kidney transplant patients without seroconversion after two doses (6-8) support an early third vaccination to improve the seroconversion rate in this vulnerable population.

\section{DATA AVAILABILITY STATEMENT}

The original contributions presented in the study are included in the article/Supplementary Material, further inquiries can be directed to the corresponding author.

\section{ETHICS STATEMENT}

Ethical review and approval was not required for the study on human participants in accordance with the local legislation and institutional requirements. The patients/participants provided their written informed consent to participate in this study.

\section{REFERENCES}

1. Jager KJ, Kramer A, Chesnaye NC, Couchoud C, Sánchez-Álvarez JE, Garneata L, et al. Results from the ERA-EDTA Registry Indicate a High Mortality Due to COVID-19 in Dialysis Patients and Kidney Transplant Recipients across Europe. Kidney Int (2020). 98:1540-8. doi:10.1016/ j.kint.2020.09.006

2. Wadei HM, Gonwa TA, Leoni JC, Shah SZ, Aslam N, Speicher LL. COVID-19 Infection in Solid Organ Transplant Recipients after SARS-CoV-2 Vaccination. Am J Transpl (2021). 21(10):3496-9. doi:10.1111/ajt.16618

3. Benotmane I, Gautier-Vargas G, Cognard N, Olagne J, Heibel F, Braun-Parvez L, et al. Low Immunization Rates Among Kidney Transplant Recipients Who Received 2 Doses of the mRNA-1273 SARS-CoV-2 Vaccine. Kidney Int (2021). 99:1498-500. doi:10.1016/j.kint.2021.04.005

4. Magicova M, Fialova M, Zahradka I, Rajnochova-Bloudickova S, Hackajlo D, Raska P, et al. Humoral Response to SARS-CoV-2 Is Well Preserved and Symptom Dependent in Kideny Transplant Recipients. Am J Transpl (2021). 21(12):3926-35. doi:10.1111/ajt.16746

5. Blazquez-Navarro A, Safi L, Meister TL, Thieme CJ, Kaliszczyk S, Paniskaki K, et al. Superior Cellular and Humoral Immunity toward SARS-CoV-2 Reference and Alpha and Beta VOC Strains in COVID-19 Convalescent as Compared to

\section{AUTHOR CONTRIBUTIONS}

JS, HS-M, KL, and EZ designed the study, JS, HS-M, and TD collected data, JS and EZ analyzed data and wrote the first draft of the manuscript. All authors reviewed the manuscript approved the submitted version of the manuscript.

\section{CONFLICT OF INTEREST}

The authors declare that the research was conducted in the absence of any commercial or financial relationships that could be construed as a potential conflict of interest.

\section{SUPPLEMENTARY MATERIAL}

The Supplementary Material for this article can be found online at: https://www.frontierspartnerships.org/articles/10.3389/ti.2021. 10060/full\#supplementary-material

the Prime Boost BNT162b2 Vaccinated Dialysis Patients. Kidney Int (2021). 100(3):698-700. doi:10.1016/j.kint.2021.07.00610.1016/j.kint.2021.07.006

6. Westhoff TH, Seibert FS, Anft M, Blazquez-Navarro A, Skrzypczyk S, Zgoura P, et al. A Third Vaccine Dose Substantially Improves Humoral and Cellular SARS-CoV-2 Immunity in Renal Transplant Recipients with Primary Humoral Nonresponse. Kidney Int (2021). 100(5):1135-6. doi:10.1016/j.kint.2021.09.001

7. Masset C, Kerleau C, Garandeau C, Ville S, Cantarovich D, Hourmant M, et al. A Third Injection of the BNT162b2mRNA COVID-19 Vaccine in Kidney Transplant Recipients Improves the Humoral Immune Response. Kidney Int (2021). 100(5):1132-5. doi:10.1016/j.kint.2021.08.017

8. Benotmane I, Gautier G, Perrin P, Olagne J, Fafi-Kremer S, Caillard S. Antibody Response after Athird Dose of the mRNA-1273 SARS-CoV-2 Vaccine in Kidney Transplant Recipients with Minimal Seologic Response to 2 Doses. JAMA (2021). 326(11):1063-5. doi:10.1001/jama.2021.12339

Copyright (C) 2022 Schimpf, Sprenger-Mähr, Davidovic, Lhotta and Zitt. This is an open-access article distributed under the terms of the Creative Commons Attribution License (CC BY). The use, distribution or reproduction in other forums is permitted, provided the original author(s) and the copyright owner(s) are credited and that the original publication in this journal is cited, in accordance with accepted academic practice. No use, distribution or reproduction is permitted which does not comply with these terms. 